\title{
LAS LECTURAS DE UN ARISTÓCRATA "DE NEGOCIOS” \\ DE FINES DEL SIGLO XVIII: LA BIBLIOTECA DEL JEREZANO \\ ANTONIO CABEZAS DE ARANDA Y GUZMÁN, I MARQUÉS DE MONTANA
}

\author{
Juan Antonio Moreno Arana \\ Maestro en Educación Primaria
}

RESUMEN: Este artículo pretende ser una contribución al estudio de las mentalidades de las élites burguesas y aristocráticas del entorno de la bahía de Cádiz a fines del siglo XVIII a través del catálogo y análisis de los contenidos de la biblioteca privada del Antonio Cabezas de Aranda y Guzmán, I marqués de Montana.

PALABRAS CLAVE: Bibliotecas privadas, mentalidades, burguesía comercial, aristocracia, Jerez de la Frontera

\section{THE READINGS OF AN ARISTOCRAT AT THE END OF THE EIGHTEENTH CENTURY: THE LIBRARY OF ANTONIO CABEZAS DE ARANDA AND GUZMAN, FIRST MARQUIS OF MONTANA}

\begin{abstract}
This article is intended as an approach to mentalities of bourgeois and aristocratic elites in the territory of the Bay of Cadiz at the end of 18th century through the catalogue and analysis of the contents of the private library of Antonio Cabezas de Aranda Guzman, I Marquis of Montana.
\end{abstract}

KEYWORDS: Private libraries, mentalities, commercial bourgeoisie, aristocracy, Jerez de la Frontera.

Recibido: 16/04/2016 /Aceptado: 03/07/2016 
Los inventarios notariales de bibliotecas privadas han despertado en las últimas décadas un notable interés por parte de los estudiosos de la historia cultural de nuestro país ${ }^{1}$. Pese a contribuciones recientes ${ }^{2}$, la catalogación y análisis de estos documentos en el marco de la ciudad de Jerez de la Frontera durante la Edad Moderna es un terreno de investigación susceptible de ampliaciones que permitan seguir delimitado y profundizando sobre el fenómeno de la lectura y de la posesión de libros. Centrándonos en un sector social concreto, como es el de la burguesía mercantil de la Andalucía del Antiguo Régimen, esta perspectiva historiográfica ligada con el estudio de las mentalidades continúa, salvando valiosas excepciones, en un estado embrionario ${ }^{3}$.

Aunando ambos puntos de análisis historiográficos, este trabajo pretende contribuir a cubrir estas lagunas. Para ello se ha elegido el estudio del inventario post mortem de la biblioteca de una personalidad que ejemplifica, a la vez que diversifica ${ }^{4}$, el comportamiento social, ideológico e intelectual de esas élites en el ámbito de la bahía gaditana de la segunda mitad del siglo XVIII: Antonio Cabezas de Aranda y Guzmán, I marqués de Montana.

\section{APUNTES BIOGRÁFICOS SOBRE EL MARQUÉS DE MONTANA}

El I marqués de Montana fallecía el 21 de mayo de 1785 a los 51 años, sin descendientes directos y sin consumar su reciente matrimonio por poderes. En cambio, tras sí dejaba un verdadero monumento a los afanes y anhelos de engrandecimiento de su modesta

\footnotetext{
${ }^{1}$ Síntesis de todo lo publicado en las últimas décadas sobre el estudio documental de bibliotecas particulares y cultura escrita durante la Edad Moderna en España se pueden encontrar en: DADSON, Trevor, J.: Libros, lectores y lecturas, Estudios sobre bibliotecas particulares españolas del Siglo de Oro, Madrid, Arco libros, 1998, pp. 7-13; ENCISO RECIO, Luis Miguel: Barroco e Ilustración en las bibliotecas privadas españolas del Siglo XVIII, Madrid, Real Academia de la Historia, 2002, pp. 15-17; INFANTES DE MIGUEL, Víctor (dir.), LÓPEZ, François (dir.), BOTREL, Jean François (dir.), BARANDA LETURIO, Nieves (coord.), Historia de la edición y de la lectura en España, 1472-1914, Fundación Germán Sánchez Ruipérez, 2003; ARIAS DE SAAVEDRA, Inmaculada: "Libros, lectores y bibliotecas privadas en el siglo XVIII", Chronica Nova, 35 (2009), pp. 15-61; NOBLE WOOD, Oliver, et al. (dirs.): Poder y saber: Biblioteca y bibliofilia en época del conde-duque de Olivares, Madrid, Centro de Estudio Europa Hispánica, 2011.

2 MORENO ARANA, Juan Antonio: Oligarquia y lectura en el siglo XVIII: La biblioteca de Manuel del Calvario Ponce de León y Zurita, regidor de Jerez de la Frontera (1794). Madrid, Bubok, 2014. En esta monografía se realiza una primera aproximación a la biblioteca del Marqués de Montana (ibidem, pp. 37-39).

3 Así lo expresa: BUSTOS RODRÍGUEZ, Manuel: "Comercio y comerciantes en la Andalucía del Antiguo Régimen: estado de la cuestión y perspectivas", Obradoiro de Historia Moderna, no 17 (2008), pp. 47-76, p. 73. Notable excepción sigue siendo la ampliamente referenciada monografía sobre la biblioteca del acomodado comerciante gaditano ligado con el movimiento ilustrado Sebastián Martínez: GARCÍA-BAQUERO, Antonio: Libro y cultura burguesa en Cádiz: las bibliotecas de Sebastián Martínez, Cádiz, 1988.

${ }^{4}$ La necesidad de abordar los casos particulares se argumenta en GARCÍA-BAQUERO, op. cit., pp. 11-12.
} 
raigambre hidalga: las fastuosas casas principales que había conseguido erigir después de un largo pleito fallado a su favor en el Real Consejo de Castilla ${ }^{5}$.

Socio y heredero de una de las más importantes casas exportadoras de vino de Jerez, la actividad mercantil - que incluyó también el tráfico de géneros textiles -, simultaneada con la producción agropecuaria, le proporcionó un crecido potencial económico que tradujo en cargos y honores: fiscal perpetuo de la Real Justicia de Jerez, capitán de las milicias urbanas de la plaza de Tarifa y finalmente, diputado del Común, cargo electo que le abrirá la puerta del, hasta la creación de este oficio capitular en 1766, fuertemente cerrado cabildo jerezano, al igual que sucedió con otros miembros de la incipiente élite burguesa jerezana, a la que Montana estaba estrechamente unido. Afín a esta nueva élite y a su decidida pugna contra los privilegios de la oligarquía local, este partido le causó grandes enemistades dentro del seno de la institución municipal.

Pero, a la par y sin contradicción alguna, Antonio Cabezas siguió los dictados de la ortodoxia socio-religiosa que le llevarían, por un lado, a obtener en 1775 el título de "Marqués de Montana" y, por otro, a crear mediante una cláusula testamentaria un patronato, financiado con sus "bienes y fincas", para dotar diversas obras pías.

\section{CONTEXTO DEL INVENTARIO DE LA BIBLIOTECA. DILIGENCIAS PARA SU VALORACIÓN Y SU POSTERIOR VENTA}

Era necesario, pues, determinar el alcance de los "bienes y fincas" del marqués que habrían de satisfacer las mandas del testamento. Se dará lugar, así, en los meses posteriores a su fallecimiento, a los autos del inventario de sus bienes. Estos se inician el 16 de diciembre de 1785 en el juzgado del Capitán General de Andalucía, por su pertenencia al fuero militar debido a su plaza de capitán de las milicias urbanas de la plaza de Tarifa, aunque al día siguiente se comisiona a la justicia ordinaria local para su ejecución ${ }^{6}$.

No fue hasta el 3 de febrero de 1786, cuando el albacea y administrador de la testamentaria del marqués, Francisco Antonio de la Tixera, "vecino y del Comercio"7 de Jerez, persona en quien Montana había depositado toda su confianza, comparezca ante el juez comisionado de los autos avisando de la existencia de "una porción de libros que inventariar y baluar perteneciente a esta disposición"8. El albacea propuso para el aprecio de estos bienes al "maestro librero" Juan Romero.

\footnotetext{
${ }^{5}$ Para la biografía de Antonio Cabezas de Aranda y Guzmán nos remitimos a MORENO ARANA, José Manuel: "El Palacio Domecq de Jerez de la Frontera y el arquitecto Juan Díaz de la Guerra", Boletín de Arte, 35 (2014), pp. 207-236.

${ }^{6}$ Archivo de Protocolos Notariales de Jerez de la Frontera (en adelante: APNJF.), tomo 2936 (oficio 11, año 1794), ff. 501-801.

7 Así es nombrado en diversas ocasiones en el documento: APNJF., tomo 2936 (oficio 11, año 1794), f. 645.

${ }^{8} \mathrm{El}$ inventario y aprecio de los libros: APNJF., tomo 2936 (oficio 11, año 1794), ff. 578-585v.
} 
Aceptada la solicitud, el 6 de febrero de 1786, se informaba al librero de su nombramiento, el cual aceptará. Sin más tardanzas, a la mañana siguiente comenzaba la "diligencia del inventario y aprecio de libros". El escribano público apuntará en los autos que acompañando al juez comisionado y al librero

"pasamos a las casas que fueron morada del señor marqués de Montana y estando en ella la señora marquesa su viuda y don Francisco Antonio de la Tixera principal apoderado y albacea se dio principio al ymbentario y aprecio de los libros de esta testamentaria".

Se necesitarán cuatro sesiones para inventariar la biblioteca del marqués, que tendrán lugar entre dicho día 6 y el 13 de febrero. Valorados los libros, los citados asistentes a la diligencia pasaron a firmar el acta. Firmaron todos, menos el librero, quien no lo hizo "porque dixo no saber", lo que no deja de ser algo llamativo y sorprendente?

\section{RECUENTO Y VALORACIÓN ECONÓMICA DE LOS LIBROS}

Se inventarió un total de 97 registros. Por lo general, cada una de estas entradas equivale a una obra. Las excepciones son las entradas 6 y 49 donde se anotan idéntico título, aunque no sabemos si son una misma edición o no, y los registros 8, 63, 65, 87 y 93 en los que no se puede afirmar que sea el registro de una o de varias obras distintas. Gracias a que quedó asentado en el inventario el número de tomos por registro se puede conocer el volumen total de los libros. Este sumaba un total de 214 tomos.

Del total de los 97 registros que componían la biblioteca, la inmensa mayoría -81tenían una valoración económica que oscilaba entre el real y los 20 reales, siguiendo la tónica habitual de precios de los libros más consumidos en la época ${ }^{10}$. La tasación de cada registro depende principalmente del número de tomos que formase o se poseyese de cada obra, así como del tipo de encuadernación. Así, el registro con mayor tasación fueron los dieciséis volúmenes del Espectáculo de la naturaleza de Pluche, que se valoraron en 240 reales, lo que equivaldría a 15 reales por tomo. A estos, les seguían los “dies y seis tomos en español de

\footnotetext{
9 Sin embargo, en 1794, cuando se le encargue el aprecio de la biblioteca de Manuel del Calvario Ponce de León, Romero sí estampará su firma (MORENO ARANA, op. cit., p. 14). En dicho aprecio e inventario, se califica a Juan Romero como "mercader de libros", una denominación que en la época hacía referencia a la ocupación de editor de impresos (GARCÍA CUADRADO, Amparo: La librería en el XVIII: el murciano Juan Polo Ruiz, Murcia, Universidad de Murcia, 2010, p. 28).

${ }^{10}$ Véase al respecto el caso de la biblioteca del noble jerezano Manuel del Calvario Ponce de León y Zurita, contemporánea a la de Montana, y que con sus 910 registros pasaba por ser una de las bibliotecas particulares más nutridas del Jerez de la época (MORENO ARANA, op. cit., p.16). Aunque no contamos con muchos estudios sobre este particular se puede poner como ejemplo: ÁLVAREZ MÁRQUEZ, María del Carmen: "La biblioteca de Don Antonio Juan Luis de la Cerda, VII Duque de Medinaceli, en su palacio del Puerto de Santa María (1673)", Historia, instituciones, documentos, nº. 15, Sevilla, 1988, p. 252. Los precios más altos lo ostentaban los libros científicos o facultativos, que normalmente tenían una menor presencia en una biblioteca no profesional: ARIAS DE SAAVEDRA, op. cit., p. 26.
} 
Historia de España por el padre Mariana”, en cien reales; los nueve tomos en francés de la cartas de madame de Sévigné, en noventa reales; y los siete libros dobles de las obras de Torres Villarroel, en ochenta reales.

El valor total de la biblioteca sumó los 1.484 reales y medio, un insignificante $0,02 \%$ de los 5.682 .954 reales en que se valoraron los activos de su fortuna, cifrados principalmente en bienes inmuebles rústicos y urbanos ${ }^{11}$, así como en una gran variedad de bienes muebles ${ }^{12}$. Los denominados como "bienes de confort", es decir, ropa, alhajas, piezas de metal, muebles, coches, guarnicionería, loza y porcelana y libros, fueron tasados en 228.588 reales. Dentro de esta cifra, que muestra el lujo en que vivía el marqués, la biblioteca no superaba el $0,6 \%$ del total ${ }^{13}$. Con todo, se movía en los parámetros habituales de precio de las bibliotecas modestas de ese momento ${ }^{14}$.

Desde el 13 de febrero de 1786, en que se concluye el inventario, hasta el 16 de mayo de 1791, las almonedas celebradas de los bienes del marqués lograron 979 reales con la venta de los libros.

Revisando las demás partidas del inventario, en concreto la referida a los muebles, encontramos registrada una "librería" valorada en 500 reales $^{15}$. Es la tasación más alta hallada en los inventarios jerezanos de la época para este tipo de objeto lígneo, un claro indicador de la fastuosidad de su ejecución o de sus materiales ${ }^{16}$.

La librería dentro de la vivienda suponemos que ocuparía una estancia de ámbito privado o de dominio de la intimidad, como serían el estudio o el gabinete, pero que no estaría exenta de abrirse para ser escenario de encuentros sociales donde representar $u$ ostentar la imagen de refinamiento cultural que las colecciones de libros ofrecían ${ }^{17}$.

\footnotetext{
${ }^{11}$ Las "casas principales" del marqués fueron valoradas en 1.140 .867 reales de vellón.

12 APNJF., tomo 2936 (oficio 11, año 1794), ff. 738-747. Entre ellos, los "géneros" textiles, tasados en 16.473 reales. Las deudas y gastos de administración de la testamentaria alcanzaron los 4.295 .433 reales de vellón: APNJF., tomo 2936 (oficio 11, año 1794), f. 746v.

13 APNJF., tomo 2936 (oficio 11, año 1794), f. 828.

${ }^{14} \mathrm{La}$ media de precios de las bibliotecas particulares jerezanas más comunes oscilaba en torno a los 1.200 reales. Por su excepcionalidad, no incluimos en este cómputo los 23.157 reales en que se tasó la ya citada biblioteca de Manuel Ponce de León: MORENO ARANA, op. cit., p. 45. Otros casos a nivel español: ibídem, pp. 46-48.

${ }^{15}$ APNJF., tomo 2936 (oficio 11, año 1794), f. 559v.

${ }_{16}$ Por ejemplo, el "estante para libros" que poseía Manuel Ponce de León y Zurita, cuyas dimensiones eran de 6 metros de largo por 3 metros de alto, se valoró en 130 reales. MORENO ARANA, 2014, p. 15. Otros casos: ibídem, pp. 15, 41. En el actual palacio Domecq se conserva un mueble de librería barroco, pero no podemos asegurar que sea el aquí inventariado.

17 FRANCO RUBIO, Gloria A., Cultura y mentalidad en la edad moderna, Sevilla, Mergablum, 1998, p. 265; BOUZA, Fernando, Corre manuscrito. Una historia cultural del Siglo de Oro, Madrid, 2001, pp. 47-49; FRANCO RUBIO, Gloria A., "La vivienda en el antiguo régimen: de espacio habitable a espacio social", Chronica Nova, 35 (2009), pp. 63-103; NOBLE WOOD, Oliver: "Vanitas vanitum et omnia vanitas: Biblioteca y bibliofilia en la literatura del Siglo de Oro", en Oliver Noble Wood, et al., op., cit., pp. 277-297.
} 


\section{DESCRIPCIÓN FÍSICA DE LOS LIBROS}

Como dijimos, cada entrada del inventario recoge el número de tomos o ejemplares que se poseía de cada obra en cuestión. Afortunadamente, pues no siempre se daba el caso, el librero no obvió este detalle en los registros. No fue, sin embargo, tan cuidadoso, y esto sí es mucho más habitual en este tipo de inventarios, en reseñar rasgos formales de los libros, tales como su tamaño, su encuadernación o su estado de conservación. No obstante, en algunos registros sí se dice algo sobre algunos de estos aspectos. En cuanto a la encuadernación, se informa que las obras Sólo Madrid es Corte, La Vida de San Clemente XIV, La Conquista de México de Solís, La Historia de España de ¿Juan de Ferreras? y la Imitación de Cristo de Kempis estaban encuadernadas en pergamino. En pasta, lo estaban los cuatros tomos de los Viajes de Enrique Wanton, el tomo de Conocimiento de las catorces aves menores de jaula, y otro sin más especificaciones, salvo la de contener una obra en francés. Esa misma especificación, la de estar en francés, es lo único que se nos dice en el registro de los dos tomos encuadernados a la rústica.

Aunque en trece entradas se informa del idioma en que estaba escrita la obra (cinco en francés, uno en inglés y siete que se remarca que estaban en español), la identificación de otras entradas del inventario ha revelado la existencia de más obras no escritas en castellano, pese a que sus títulos fuesen registrados en este idioma. Se puede, así, decir con certeza que treinta y dos obras estaban escritas en francés (entre las que incluimos los nueve tomos que se expresa estar en este idioma, pero sin que se especifique su título ni su contenido). En inglés constan dos títulos: Obra moral de Seneca editada en Londres en 1775 y el epistolario Letters written (Londres, 1777).

Este acceso directo a la producción editorial de los dos principales focos culturales de la época presupone un conocimiento de estas lenguas extranjeras por parte de nuestro lector. La biblioteca también da respuesta a esta cuestión: contenía varias gramáticas y libros bilingües para el aprendizaje del francés y del inglés ${ }^{18}$.

Hay que subrayar, igualmente, que junto a ese importante núcleo de obras en francés, otra manifestación de esta supremacía e influencia cultural son las abundantes

\footnotetext{
18 Era algo común y lógico la presencia de estas gramáticas en bibliotecas con libros en dichos idiomas (ENCISO RECIO, op. cit., p.79). La producción editorial española de obras para la enseñanza de lenguas extranjeras tuvo un importante incremento durante el siglo XVIII, muestra del interés por la producción cultural de fuera de nuestras fronteras (ÁLVAREZ DE MIRANDA, Pedro, "Libros para el aprendizaje de lenguas extranjeras”, en Víctor Infantes de Miguel (dir.), François López (dir.), Jean François Botrel (dir.), Nieves Baranda Leturio (coord.), op. cit., pp 434-439. Otras bibliotecas jerezanas contemporáneas que poseían gramáticas francesas fueron la de la propietaria agrícola Sebastiana Lizano y la que compartían el noble Joaquín Ponce de León y su esposa Hipólita Trujillo Ponce de León (MORENO ARANA, op. cit., pp. 39, 35).
} 
traducciones de obras del país del otro lado de los Pirineos que hacían sudar a las prensas españolas en aquellos años ${ }^{19}$. Una supremacía cultural que Montana asume con sus lecturas. Las obras escritas en francés traducidas al castellano alcanzaba la cifra de quince ${ }^{20}$. Si las sumamos a las treinta y dos en su versión original tenemos que el 48,5\% de la biblioteca del ennoblecido comerciante jerezano era de producción gala.

Otras obras traducidas al castellano que aparecen en el inventario estaban escritas originalmente en latín (3), en italiano (2) y en inglés, catalán y portugués, éstas con una obra respectivamente ${ }^{21}$.

\section{CONTENIDOS Y TEMÁTICAS}

Antes de comenzar la descripción temática de la biblioteca de Montana hay que señalar que no se ha podido incluir en este análisis los registros 8, 91, 93. Esto se debe a que el inventario en estos concretos registros rehúsa ofrecer referencia alguna que permita identificar el título o al autor de la obra. Únicamente se aclara cuál era la encuadernación, cuántos los tomos, el precio y la característica común a los tres, la de estar escritas en francés. El detalle de su procedencia hace pensar que esta falta de precisión pudiera ser una precaución para evitar problemas con las autoridades inquisitoriales.

a) Geografía e Historia. Dejando a un lado esos tres registros de los que ignoramos su contenido ( $3 \%$ de la biblioteca), es la Historia con 28 obras, con algunas menciones geográficas en algunas de ellas, la temática de mayor presencia: el 28,8\% del total.

Ampliamente representada en todas sus vertientes, se pueden señalar, en primer lugar, a Buffier y a Clemente con sus respectivas Historias Universales. Junto a ellas se puede colocar la Historia de successos memorables del mundo que trata la Historia bíblica. La Historia General de España cuenta con las monumentales obras de Mariana y ¿Ferreras? y con la edición original en francés de la Historia de las revoluciones de España de Joseph d'Orléans. La Historia Antigua es estudiada en las obras de Heródoto, los comentarios de Julio Cesar y en los contemporáneos de Rollin y de Patin, este último a través de la

\footnotetext{
19 Sobre la influencia de la producción editorial francesa en la España del Siglo XVIII: LAFARGA MADUELL, Francisco (coord.): La traducción en España (1750-1830): lengua, literatura, cultura. Madrid, 1999; GARCÍA GARROSA, María José; LAFARGA, Francisco: El discurso sobre la traducción en la España del siglo XVIII: estudio y antología, Barcelona, 2004, pp. 3-77; ALBIAC BLANCO, María Dolores, Historia de la literatura española, 4, Razón y sentimiento 1692-1800. Barcelona, Crítica, 2015.

${ }^{20}$ Entradas: 3, 6, 10, 12, 16, 18, 30, 32, 39, 41, 56, 72, 75, 81, 82.

${ }^{21}$ Entradas: 1 (inglés/italiano); 15, 92, 97 (latín); 68, 95, (italiano); 76 (portugués); 84 (catalán).
} 
numismática, ciencia que tuvo gran predicamento en aquellos años, dada su insistente presencia en los inventarios ${ }^{22}$.

Este interés por la Historia, uso o gusto lector común y corriente entre los lectores de la época, también mira hacia su propia ciudad. Así, poseía uno de los escasos libros de historia jerezana dados a la imprenta hasta ese momento: la colección de efemérides Año Xericiense, publicada en Sevilla en 1755.

Otros títulos son los referidos a la historia y geografía de las colonias americanas (la Conquista de México de Solís, el Orinoco ilustrado y la Noticia del establecimiento y población de las colonias inglesas en la América Septentrional). Por su parte, la descripción geográfica, antropológica y natural de "las islas de las indias orientales" contaba con la relación en francés, con ilustraciones, de los viajes de exploración de François Leguat.

La Historia del imperio Otomano tampoco podía faltar en esta biblioteca, que contaba con dos títulos al respecto.

Sobre Historia de ciudades, Montana hubo de leer con pausada atención, dada sus relaciones con súbditos ingleses y franceses, la Historia de Gibraltar por López de Ayala y la Description de la ville de Paris, publicada en la propia capital francesa en 1753. En el mismo sentido de apropiación de las coordenadas culturales del país galo se entendería el ejemplar de "la chronología de Francia" de Hénault.

También se anota un ejemplar referido a la historia de orden militar de San Jorge: Origen, y fundacion de la imperial religión militar, y cavalleria constantiniana, llamada oy de San Jorge (Sevilla, 1676) de Cepeda y Guzmán. Relacionado con lo militar está el texto que recoge la biografía del príncipe Eugenio de Saboya. Esta sección biográfica, se completa con otras obras con un evidente carácter hagiográfico y moralizante, hablamos, así, de las vidas de Juan Pecador, el papa Clemente XIV, Fr. Tomás de Vidal, arzobispo de la ciudad de Mesina, de San Francisco de Paula y el libro de semblanzas Retratos de jesuitas.

b) Lengua y Literatura. A continuación de la Historia, los tratados de lenguas extranjeras y la literatura fueron las lecturas en las que más horas se ocupó Montana. Con ocho obras de carácter filológico y doce puramente literarias, significaban el 20,6\% de la biblioteca. Nada menos que cuatro de estos textos estaban dirigidos al aprendizaje de idiomas extranjeros; dos gramáticas francesas, un libro bilingüe de expresiones en francés y español y una gramática inglesa, herramientas imprescindibles para acceder a textos como

22 ENCISO RECIO, op. cit., p. 40. En el Jerez de la segunda mitad del XVIII están documentados tratados sobre numismática antigua en bibliotecas como las de Manuel del Calvario Ponce de León y la de Sebastiana Lizano (MORENO ARANA, op. cit., pp. 22, 39). Pese a ello, este interés no tiene correspondencia en los citados inventarios con la presencia de algún monetario o colección numismática. 
las Oeuvres del autor y crítico literario Nicolás Boileau, que también se hace hueco en este apartado.

Al contrario, el estudio de su lengua materna sólo estaba representado en Arte poética española de Diego García Rengifo.

Completa estas obras de carácter filológico, la excelente traducción, a decir de los que aprueban su impresión, de $\mathrm{D}^{a}$. María Catalina de Caso del Modo de enseñar y estudiar las bellas letras (Madrid, 1755) del historiador y pedagogo francés Charles Rollin. Una obra que exalta la "buena educación", aquella que instruye en "la ciencia, las costumbres y la religión", y el estudio de las "Artes y las Ciencias" como único camino, según el autor y su traductora, que tiene la persona para "elevarse" por encima de los demás. Una obra que, en su parte filológica, propone las claves para el estudio del francés -como no- junto al del griego y del latín. Rollin también se ocupa de la poesía, con especial mención a Homero.

El Nuevo estilo y formulario de escribir cartas misivas y responder a ellas en todos los géneros y especies de correspondencia a lo moderno, del que se harán numerosas ediciones a lo largo del siglo XVIII, fue un útil, aunque encorsetado, recurso retórico que daba respuesta a las constantes y variadas relaciones epistolares, tanto en forma como en destinatarios, a las que estaban obligadas a establecer personas del estatus social de Antonio Cabezas. Quizás en este mismo sentido haya que interpretar los varios epistolarios, que veremos más adelante.

El repaso por las lecturas literarias debe comenzar ineludiblemente por uno de los éxitos editoriales del XVIII europeo, Las aventuras de Telémaco, del arzobispo de Cambray, François Fènelon, publicada originalmente en 1699. A pesar de que en castellano se realizaron diversas ediciones desde principios de siglo, el ejemplar de Montana fue una edición francesa. $\mathrm{Y}$ es que el rasgo que caracteriza a estas lecturas del marqués es su afrancesamiento: acompañaban al Telémaco, Les nouveaux contes des fées (ediciones desde 1699 a 1752) de madame d'Aulnoy, la Histoire de Miss Jenny (1765) de madame Riccoboni, la colección de novelas sentimentales Les Journées amusantes (1766) de madame de Gomes obra ésta que no será traducida al castellano hasta 1792 - y finalmente los relatos orientales de Les mille et un jour: contes persans (varias ediciones entre 1766 y 1783) de Pétis de la Croix, que hemos propuesto como identificación de los "cuentos árabes" anotados en el registro 38 .

Como se observa, el gusto literario del marqués se inclina hacia los relatos cortos y las narraciones de carácter rocambolesco y extraordinario - como son los citados "cuentos de hadas" de madame d'Aulnoy, los cuentos orientales o la extravagante novela alegórica- 
moral Viajes de Enrique $W$ anton - y la novela sentimental francesa contemporánea de la que eran exponentes las novelistas Riccoboni y Gomes.

La literatura española sólo está presente en el inventario en una recopilación de “comedias" u obras de Calderón de la Barca ${ }^{23}$ y las novelas Poema trágico Gerardo Español (ediciones entre 1615 y 1732) de Gonzalo de Céspedes y Engaños y desengaños del profano amor (eds. entre 1687 y 1756) por el Conde de Villasalto. Hay que señalar otro registro que recoge un tomo conteniendo "varias comedias" de las que no se especifican ni título ni autor.

Por último, hay que incluir en este apartado dos obras de género epistolar, ambas en su edición original: por un lado, los nueve tomos de las cartas de la marquesa de Sévigné. Por otro, las Letters written by the late Right Honourable Philip Dormer Stanhope, Earl of Chesterfield, to his son, Philip Stanhope (Londres, 1777). Estos epistolarios de índole familiar, en especial el Recueil des lettres de Madame la Marquise de Sevigné alcanzaron gran popularidad dando lugar a múltiples ediciones durante todo el siglo. Hay que hacer notar que la edición de estos epistolarios no tuvo como única motivación el simple entretenimiento o la exposición ideológica que se podía infiltrar en ellos. En realidad, suponían modelos de retórica epistolar para sectores sociales abiertos a las modas de sociabilidad, a la llamada "sociedad galante", que la supremacía cultural francesa ejercía sobre las clases burguesas y aristocráticas europeas y españolas. Para nuestro marqués, su relación con comerciantes europeos, con personajes pertenecientes a la élite económica y social, e incluso, intelectual de la época, requeriría una retórica para misivas más avanzada y actualizada que la que podía ofrecer el encorsetado y anacrónico formulario de escribir cartas misivas ${ }^{24}$.

c) Religión y moral cristiana. Representado el retroceso que la religión tiene en las bibliotecas particulares del siglo XVIII ${ }^{25}$, en $\mathbf{9 , 3 \%}$ de la biblioteca lo ocupaban nueve títulos de religión. Dominaban los dirigidos a desarrollar la vida espiritual y la devoción. Destaca especialmente la omnipresente Imitatio Christi, de Tomás de Kempis y la Introducción a la vida devota de Francisco de Sales, referentes de la corriente ascética y mística propia de la sociedad barroca contrarreformista. Hay que subrayar la curiosa, o cuanto menos, llamativa presencia de dos libros litúrgicos en francés entre los anaqueles de Montana, Le petit eucologe

\footnotetext{
${ }^{23}$ Calderón fue el dramaturgo barroco español que mayor aceptación tuvo en todos los sectores sociales en el XVIII, difundiéndose muchas de sus obras mediante la edición en pliegos sueltos: ENCISO RECIO, op. cit., p. 79; LÓPEZ, Joseph, “Los clásicos del pueblo”, en Víctor Infantes de Miguel (dir.), François López (dir.), Jean François Botrel (dir.), Nieves Baranda Leturio (coord.), op. cit., pp. 473-474.

${ }^{24}$ SÁNCHEZ ESPINOSA, Gabriel: "Madame de Sévigné y la carta familiar en España durante el siglo XVIII”, en Mercedes Boixareu Vilaplana y Roland Desné (eds.); Ester Juan (col.), Recepción de autores franceses de la época clásica en los siglos XVIII y XIX en España y en el extranjero, Madrid, Universidad Nacional de Educación a Distancia, 2001, pp. 111-123

${ }^{25}$ ENCISO RECIO, op. cit., p.38.
} 
ou Livre d'église (Paris, 1777) y Manuel des Prières. También es de destacar el tratado sobre el oficio sacerdotal Instrucción de sacerdotes (Barcelona, 1746).

No existe mención a autores como Fleury, que desde un punto vista ideológico podría ubicar a nuestro marqués en tendencias cercanas a la religiosidad ilustrada, salvo que las busquemos disueltas en otros textos tales como el ya mencionado tratado de Rollin ${ }^{26}$.

d) Ciencias Aplicadas. Tratados y Libros Técnicos. Esta sección temática la forman nueve títulos y constituye el 9,3\% de total de la biblioteca. Quizás sea esta la sección que mejor retrata a su propietario. Como propietario agrícola, Cabezas disponía de dos de los tratados relacionados con la agricultura de mayor relevancia en la época: Herrera y fray Miguel Agustín. Su faceta de productor y exportador de vinos justificaría la presencia de un "quaderno de hacer vino", que puede identificarse con El arte de hacer el vino del autor francés Maupin, traducido al castellano en 1777.

El caballo era un signo distintivo de la nobleza que en la ciudad de Jerez estaba profundamente arraigado y asentado. Como ganadero y como noble, su formación libresca al respecto se materializó en los cinco tratados relacionados con la cría, sanidad y manejo artístico del caballo, entre ellos las ediciones francesas de Nouvean Traité de Cavalerie del duque de Newcastle y Le Parfait mareschal de Solleisel.

e) Ciencias. La enciclopédica y voluminosa obra de Historia Natural, Espectáculo de la naturaleza, o conversaciones a cerca de las particularidades de la bistoria natural de Pluche, de la que se contaba con un tomo en su edición original francesa, así como otros dieciséis de la traducción castellana, ocupa el lugar más destacado entre los libros temática científica, que con nueve registros constituía el $\mathbf{9 , 3 \%}$ de la librería.

Dos compendios de matemáticas (Puig y Godin), junto a un posible tercero, (quaderno por guarismo por Cusant) muestran el interés por este conocimiento. Relacionado con el uso de las matemáticas para la medida del tiempo está el lunario perpetuo de Jerónimo Cortés, obra con la que relacionamos el registro "tomo de Lunarquañadido (sic) en tres reales". Imprescindible por sus múltiples aplicaciones prácticas, ya fuera para el calendario anual agrario como para el litúrgico.

La prevención de la salud, o "economía de la salud del cuerpo humano" son los temas del Tratado de las enfermedades mas frequentes de las gentes del campo de Tissot, (Madrid, 1774, 1776) y de los dos tomos de las Obras medico-chirurgicas de Madama Fonquet, (varias

26 Ejemplos de esa religiosidad ilustrada sí la encontramos, en cambio, en la extensa biblioteca de su convecino Manuel del Calvario Ponce de León (MORENO ARANA, op. cit., p. 49). 
ediciones entre 1748 y 1771). Obras que pueden ponerse en relación tanto con su faceta de propietario agrícola como de militar.

Finalmente, aunque los diccionnaire portatif abundaron en la Francia del siglo XVIII, ocupándose de los más diversos temas (históricos, religiosos, geográficos, filosóficos...), aventuramos la identificación del desconocido Veausar, autor del diccionario portátil registrado en la entrada 25 del inventario, con Jean-François de Lavoisien, cuyo nombre habría sido en ella incorrectamente trascrito. El Dictionnaire portatif de Lavoisien, publicado en Paris en 1764 y en 1771, es una miscelánea en la que se trata varios campos de la Ciencia.

f) Jurídicos y Legislativos. Los libros normativos o de práctica jurídica -cuatro registros (4,2\% de la biblioteca)- estaban relacionados con situaciones que para un noble con ocupaciones militares le eran cotidianas. Y qué más cotidiano y a la vez más trascendente para un aristócrata que el heredar: así lo demuestra la Practica de testamentos y modos de suceder (Madrid, 1755) de Ripia. O qué situación menos ajena a este estamento que el pleitear, palabra que bien conocía Antonio Cabezas: el vademécum de jurisprudencia española Libreria de jueces tampoco podía faltar, pues, en su biblioteca.

De manejo casi diario también le serían los libros de derecho o legislación militar como el tomo del Reglamento y ordenanza de S.M. para el exercicio, evoluciones, y maniobras de la Cavallería y dragones montados de sus exercitos y otros puntos relativos al servicio de estos cuerpos (Madrid, 1774) o los “tres libros colección de ordenanzas militares”.

g) Pensamiento. Consta de cuatro registros (4,2\% de la biblioteca). La filosofía moral ocupa tres registros compuestos por un tomo de la Filosofía moral (Madrid, 1770) de Enmanuele Tesauro "derivada de la alta fuente del grande Aristoteles Stagirita” y por las obras morales de Seneca en dos registros, una de una edición inglesa y otra, posiblemente, en francés. Una filosofía estoica que casa mal con el afán de lujo exterior y de reconocimiento social del fundador del Marquesado de Montana.

El cuarto registro que hemos clasificado dentro de las materias filosóficas es la teoría del conocimiento que expone el filósofo y médico valenciano Andrés Piquer, uno de los autores más sobresalientes de los Novatores, Lógica moderna o arte de hallar la verdad y perfeccionar la razón, que incide de nuevo en el alto valor que para Montana hubo de tener la formación intelectual. 
h) Educación de nobles. Este 3,1\% del total de los registros inventariados está expresamente destinado a poner las pautas para dirigir una educación integral -intelectual, física, social y moral- de los individuos pertenecientes al estamento noble. Hablamos de los tratados de Le Maitre de Claville, Tratado del verdadero mérito del hombre (Madrid, 1741), del El noble bien educado (Madrid, 1776) que firma Antonio Vila Camps, y La verdadera política de los bombres de distinción (Madrid, 1775).

i) Otros géneros. En otros géneros, pues consideramos que tienen rasgos propios que no pueden amoldarse a una materia determinada, pero que están relacionados con su faceta como militar y noble. Tenemos así los ensayos-crónicas militares Journal du siége de Berg-op-zoom: avec réflexions militaires, (Paris, 1756) y Loisirs d'un soldat au régiment des gardes francoises (Paris, 1760). Asimismo, el ensayo moral en francés "consideraciones de duelos" (Paris, 1746) de Basnage. Todos ellos, componía el 3,1\% de la biblioteca.

j) Política. La principal doctrina política que mostraban los anaqueles de Montana era el Tacitismo, corriente ampliamente implantada en España desde el siglo anterior y que aún seguía presente en bibliotecas del todo el país. Se registran, así, en el inventario: Alma o Aphorismos de Cornelio Tácito, Amberes, 1651; ¿Commentarios politicos a los Annales de Cayo Vero Cornelio Tácito, Madrid, 1687?

El otro libro que completa este 3,1\% de la librería tenía una mayor actualidad; se trataba de Obra pía, y eficaz modo para remediar la miseria de la gente pobre de España (Madrid, 1750, 1767) del político y economista Bernardo Ward, iniciador y promotor de los proyectos de regeneración económica y social en los centró sus esfuerzos la política de la España ilustrada de la segunda mitad del XVIII. Esta obra, única de tema explícitamente ilustrado presente en el inventario ${ }^{27}$, abogaba por un sistema secularizado de asistencia social, el fomento de la agricultura, la industria y el comercio como solución al problema de la pobreza ${ }^{28}$.

k) Obras Misceláneas. Finalizamos esta clasificación temática o de materias de los libros de Montana con dos obras (2\% de la biblioteca) que hemos venido a denominar

27 En cambio, los títulos abiertamente de temática ilustrada abundaban en las bibliotecas de sus contemporáneos Sebastiana Lizano y Manuel Ponce de León (MORENO ARANA, op. cit., 39, 49-52) En el contexto general predomina esta misma disparidad en cuanto a la presencia de estas obras en bibliotecas particulares: ARIAS DE SAAVEDRA, op. cit., pp. 30-61,

${ }_{28}$ Un problema con el que Montana estaría bastante familiarizado, pues sus actividades agrícolas daban salario a unas 500 personas de Jerez y su entorno: MORENO ARANA, José Manuel, op. cit., p. 209, nota 9. 
misceláneas. Y qué mayor autor misceláneo que Diego de Torres Villaroel. Toda su producción literaria y científica quedó compendiada en Libros en que están relatados differentes quadernos physicos, médicos, astrológicos, poéticos, morales y mysticos, de la que se anotan "siete libros dobles".

El otro título que puede considerarse como miscelánea es el Libro bistórico político sólo Madrid es corte, y el cortesano en Madrid (Barcelona, 1698) de Alonso Núñez de Castro, donde se expone un amplio y variado abanico de noticias, conocimientos, habilidades y advertencias para todo pretendiente a medrar en la Corte de Madrid.

Tabla 1. Clasificación porcentual de materias de la biblioteca de Antonio Cabezas de Aranda y Guzmán, marqués de Montana.

\begin{tabular}{|c|c|c|}
\hline MATERIA & TÍTULOS/REGISTROS & $\%$ \\
\hline Geografía e Historia & 28 & 28,8 \\
\hline Lengua y Literatura & 20 & 20,6 \\
\hline Religión y Moral & 9 & 9,2 \\
\hline Ciencias aplicadas & 9 & 9,2 \\
\hline Ciencias & 9 & 9,2 \\
\hline Jurídicos & 4 & 4,1 \\
\hline Pensamiento & 4 & 4,1 \\
\hline Educación de nobles & 3 & 3,1 \\
\hline Otros géneros & 3 & 3,1 \\
\hline Política & 3 & 3,1 \\
\hline Misceláneas & 2 & 2 \\
\hline Sin identificar & 3 & 3,1 \\
\hline Total & 97 & 100 \\
\hline
\end{tabular}




\section{CONCLUSIONES: ANTONIO CABEZAS DE ARANDA Y SU BIBLIOTECA EN SUS CONTEXTOS}

Durante la Edad Moderna, la posesión libraria o, mejor, la conformación de bibliotecas privadas está relacionada, por lo general, con sectores con un cierto poder adquisitivo y con las élites socio-culturales. No obstante, dicha situación social no implicaba la formación de una librería de cierta importancia, algo que pone sobre la mesa de debate las motivaciones para formar o no una biblioteca, a la vez que apunta hacia la heterogeneidad del fenómeno $^{29}$. El caso de Antonio Cabezas es ilustrativo al respecto. Su fortuna, que sobrepasaba ampliamente los cinco millones de reales - pocos convecinos de Montana reunieron un caudal de este nivel ${ }^{30}$ - sólo aparejó una biblioteca con noventa y siete registros (240 volúmenes), un volumen de libros que tipifica una biblioteca de tamaño medio-bajo, tanto a nivel nacional como local ${ }^{31}$. Se podría decir que fue la biblioteca de un simple lector, de una persona interesada por la cultura escrita, pero no la de un bibliófilo que amontona innúmeros lotes de libros de toda ralea.

Esta biblioteca surge de un interés lector y de la búsqueda de la utilidad práctica que ofrece la lectura. Fue, por tanto, una biblioteca de creación personal. La adquisición de sus libros no estuvo determinada, al menos en su mayor parte, por contingencias como herencias o por compras de otras bibliotecas, sino en atención a sus intereses a lo largo de su vida ${ }^{32}$; así lo demuestra que prácticamente todos textos impresos que había atesorado eran de ediciones contemporáneas.

\footnotetext{
${ }^{29} \mathrm{El}$ estudio de inventarios post-mortem para el Jerez de la segunda mitad del siglo XVIII arroja un porcentaje del 5,6\% de posesión de libros; datos y consideraciones al respecto en: MORENO ARANA, op. cit., pp. 3435. Sobre la no relación directa entre volumen del capital acumulado por una persona o la división socioprofesional y la posesión de libros véase, por ejemplo: GARCÍA-BAQUERO, op. cit., p. 35; BUIGUES, JeanMarc, "Los lectores: oficios, profesiones y estados", en Víctor Infantes de Miguel (dir.), François López (dir.), Jean François Botrel (dir.), Nieves Baranda Leturio (coord.), op. cit., pp. 424-433; ÁLVAREZ SANTALÓ, León Carlos, "Libro y sociedad en la Sevilla del Antiguo Régimen (1700-1834): un diagrama socioeconómico", en Thomas Calvo y Alain Musset (Dir.), Des Indes occidentales à l'Amérique latine, volumen 1, México, Centro de estudios mexicanos y centroamericanos, 2009, pp. 261-277; MORENO ARANA, op. cit., p. 40. A la realidad sesgada que describen los inventarios post-mortem respecto a las difusión de las prácticas lectoras hay que contraponer otras, como la literatura en pliegos sueltos o "de cordep", que, pese a su popularidad, rara vez pueden vislumbrarse, por su carácter efímero y no venal, a través de estas fuentes documentales. En este sentido, es necesario recordar el pionero ensayo de CHARTIER, Roger, El orden de los libros. Lectores, autores, bibliotecas en Europa entre los siglos XIV y XVIII, Barcelona, Gedisa, 1996, pp. 27-28. Más recientemente, abundan en este fenómeno: LÓPEZ, François y GARCÍA COLLADO, María Ángeles, en Víctor Infantes de Miguel (dir.), François López (dir.), Jean François Botrel (dir.), Nieves Baranda Leturio (coord.), op. cit., pp. 391-397, 368-375, 471-480.

${ }^{30}$ Niveles de renta en Jerez en el siglo XVIII: GONZÁLEZ BELTRÁN, Jesús Manuel: “Aproximación social a la estructura del capital: Jerez de la Frontera 1750-1790”, Trocadero, no. 12/13 (2000).

31 Ejemplos en: GARCÍA-BAQUERO, op. cit., p. 35; BUIGUES, op. cit., pp. 429-430; ARIAS DE SAAVEDRA, op. cit., pp. 27-61. MORENO ARANA, op. cit., pp. 46-47;

32 Sobre las vías y motivaciones para la formación de una biblioteca personal: DADSON, op. cit., pp. 28-48.
} 
Dejando aparte tendencias de lectura generales de la época, como es la destacada presencia de la Historia ${ }^{33}$, son las demás temáticas presentes en la biblioteca - y sus porcentajes dentro de ésta- las que realmente perfilan o identifican al lector. Primero, como individuo de una determinada clase social u oficio, y en segundo lugar, como persona con intereses particulares, como serían, en este caso, por ejemplo, los relacionados con el tema agrario o comercial.

Perteneciente a la pequeña nobleza jerezana ajena a la oligarquía local, Antonio Cabezas fue un hombre hecho a sí mismo gracias al comercio vitivinícola y textil que lo lleva a la cúspide económica, para luego encaramarlo a la cúspide social del Jerez de la segunda mitad del XVIII con la consecución del título de marqués. Como aristócrata ex novo, no existía en su biblioteca atisbos, como sería propio en la vieja nobleza ${ }^{34}$, de obras históricas o genealógicas sobre linajes nobles, en las que ver explayadas las grandezas de una larga estirpe con la que entablar vínculos familiares. Sí contaba, en cambio, con títulos relacionados con la cultura nobiliaria, como los tratados relacionados con la cría y el manejo artístico del caballo, los temas jurídicos, políticos y militares, todos libros de común presencia en las bibliotecas de individuos de ese estamento ${ }^{35}$. Una esfera donde hay que encuadrar también los tratados de educación de nobles y de cortesanos, donde el neófito se preparaba para moverse en las procelosas aguas de un estamento que miraba de reojo a los advenedizos.

No se puede negar que el cambio de mentalidad promovido por la monarquía borbónica en relación al comportamiento social y político de la nobleza, en el que va tomando una especial relevancia la preparación intelectual, caló en Montana; la variedad temática de sus lecturas es buen ejemplo de ello. Y aunque los títulos de la Ilustración sean escasos - hecho habitual en bibliotecas ajenas a los círculos o élites ilustradas ${ }^{36}$ - sí son representativos, tal serían los textos de Ward o de Rollin. Sin ir más lejos, Charles Rollin exaltaba las "utilidades del estudio de las Artes y Ciencias" para la "elevación" de la persona, además de la "capacidad" que proporcionaba para los "negocios", asunto, éste, no menos secundario para una personalidad, como la de Montana, sustentada en los tratos comerciales y en los pleitos judiciales.

\footnotetext{
${ }^{33}$ ENCISO RECIO, op. cit., p. 37; ARIAS DE SAAVEDRA, op. cit., pp. 29-30.

34 Por su cercanía espacial y temporal, hay que referir, nuevamente, el ejemplo de la biblioteca de Ponce de León y Zurita: MORENO ARANA, op. cit., p. 21.

35 ARIAS DE SAAVEDRA, op. cit., pp. 32-35; ENCISO RECIO, op. cit., pp. 120-122; MORENO ARANA, op. cit., pp. 48-53.

36 BUIGUES, op. cit., p. 430.
} 
El interés por la formación intelectual, sin embargo, no tiene su correlación en el inventario en lo referido al campo del Arte, tema que por sus relaciones sociales y por su vida volcada hacia el lujo debería haberle interesado.

La encuadernación de pliegos sueltos de literatura de cordel, relaciones o prensa periódica, textos efímeros que sin duda Montana habría leído, quizá se esconda tras registros tan indeterminados como el 8, 63, 91 y 93.

Pero volviendo a esa estrecha vinculación con el comercio instalado a caballo entre Jerez y Cádiz, es innegable que ésta es la que marca y define a Cabezas. Sólo hay que repasar la lista de sus deudores y acreedores instalados en el emporio gaditano para comprobar el destino y procedencia de sus productos y el origen de su patrimonio; la práctica totalidad eran súbditos británicos ${ }^{37}$. Y es interesante señalar que entre sus deudores gaditanos se encontraba el comerciante, voraz comprador de libros y coleccionista de obras de arte Sebastián Martínez ${ }^{38}$, pues su posible influencia sobre nuestro lector no debería soslayarse. Así parecen demostrarlo los paralelismos entre ambas bibliotecas en relación a sus contenidos - exceptuando la temática artística que tanto caracteriza a la biblioteca de Martínez - y a la destacada presencia del francés y de la creación intelectual francesa ${ }^{39}$.

Dichos tratos comerciales conllevarían también otro tipo de relaciones más personales que tienen su correspondencia en los gustos lectores o en la utilización formativa de la cultura escrita. No vemos otro origen para la amplísima muestra de obras de diverso contenido en francés y también alguna en inglés, que van acompañadas por sus respectivas gramáticas, lo que aproximaría a esta biblioteca al modelo "ilustrado" 40 . No se trataría sólo de la introducción y adopción, a través de la lectura, de las afrancesadas modas "galantes" que hacían furor entre las clases altas del momento ${ }^{41}$, sino que se demostraría la importancia que el conocimiento cultural e idiomático pudo haber significado como estrategia para estrechar lazos con sus socios británicos y franceses ${ }^{42}$. ¿Qué otra explicación

\footnotetext{
37 Constatamos apellidos del Comercio gaditano como Murphy, Noble, Power, Purcell, Thompson, Sebastián Martínez, etc...: APNJF., tomo 2936, oficio 11, año 1794, ff. 641, 643, 666. Como curiosidad, diremos que Pedro Domecq, con cuyo apellido acabará ligado al "palacio" de Montana tras adquirirlo sus descendientes en el siglo XIX, aparece en los autos como apoderado de la compañía de Jacobo y Eduardo Gough cobrando un pagaré de 3.180 pesos dado por Antonio Cabezas en 1784 (APNJF., tomo 2936, oficio 11, año 1794, f. 229v. (foliación interna de los autos del inventario).

${ }^{38}$ Es interesante señalar que Martínez poseyó una bodega en Jerez: GARCÍA-BAQUERO, op. cit., p. 30.

${ }^{39} \mathrm{El}$ afrancesamiento cultural de la biblioteca de Martínez en: GARCÍA-BAQUERO, op. cit., p. 40.

${ }^{40}$ Las líneas definitorias de los modelos de biblioteca "barroca" e "ilustrada" en: ENCISO RECIO, op. cit., pp. 34-41.

${ }^{41}$ LORENZO ÁLVAREZ, Elena de: "La sociabilidad ilustrada: instinto de conservación, compromiso civil y práctica social”, en CANTOS CASENAVE, Marieta: Redes y espacios de opinión pública: de la Ilustración al Romanticismo: Cádiz. América y Europa ante la Modernidad: 1750-1850, Cádiz, 2006, pp. 431-444.

42 Sus relaciones con el dinámico grupo de comerciantes franceses asentados en Jerez en: MALDONADO ROSSO, Javier: La formación del capitalismo en el marco del Jerez. De la vitivinicultura tradicional a la agroindustria vinatera moderna (siglos XVIII y XIX), Madrid, 1999, p. 123.
} 
podría tener su francofilia o su anglofilia - manifestada incluso en su colección pictórica en el retrato de la británica duquesa de Cumberland - que la de congraciarse con ellos? ${ }^{43}$

En efecto, podemos apreciar una serie de cambios mentales y sociales de índole burguesa, entre los que son especialmente reseñables las nuevas concepciones educativas en torno a la mujer. Unos nuevos roles plasmados en el epistolario de Sévigné o en la literatura sentimental de Riccoboni, que trazan un perfil educativo y de comportamiento social activo para la mujer de la cosmopolita "aristocracia comercial", una formación en vista a su papel de pieza clave dentro de los juegos de alianzas entre familias de esta pujante élite ${ }^{44}$.

Como expresó Chartier, la multiplicación de lo impreso durante la Edad Moderna trasformó las formas de sociabilidad, autorizó pensamientos nuevos y modificó las relaciones con el poder ${ }^{45}$. En este sentido, la biblioteca del marqués de Montana ejemplifica cómo la cultura escrita fue para algunos miembros de esa burguesía ennoblecida del ámbito gaditano un instrumento formativo en todos los órdenes, no sólo de recreo, además de vehículo tanto de introducción y adopción de nuevos modelos de sociabilidad burguesa como de afirmación aristocrática.

\footnotetext{
${ }^{43}$ El cuadro se inventariaba en 45 reales: APNJF., tomo 2936, oficio 11, año 1794, f. 557v.

${ }^{44}$ FERNÁNDEZ PÉREZ, Paloma: “Mujeres y burguesía en el Cádiz del siglo XVIII”. La burguesía española en la Edad Moderna, Valladolid, 1996, pp. 281-298; BOLUFER PERUGA, Mónica: "Pedagogía y moral en el siglo de las luces: las escritoras francesas y su recepción en España", Revista de Historia Moderna, 20 (2002); BOLUFER PERUGA, Mónica: "Representaciones y prácticas de vida: Las mujeres en España a finales del Siglo XVIII”. Cuadernos de Ilustración y Romanticismo, 11 (2003), pp. 3-34; BOLUFER PERUGA, Mónica: "Mujeres e ilustración: Una perspectiva europea". Cuadernos de Historia Moderna. Anejos 2007, VI, Madrid, 2007, pp. 181-201. MORENO ARANA, Juan Antonio: La Educación en Jerez de la Frontera en el siglo XVIII, Madrid, Bubok, 2012, pp. 225-235.

${ }^{45}$ CHARTIER, Roger, El mundo como representación, Barcelona, Gedisa, 1992, p. 78.
} 


\begin{abstract}
APÉNDICE
Catálogo de la Biblioteca de ANTONio Cabezas de ARANDA y GuZMÁn, I MARQUÉS DE MONTANA (1786) ${ }^{46}$.
\end{abstract}

1. Primeramente quatro tomos de Enrrique waton en pasta y en español en cinquenta y seis reales. [SERIMAN, Zaccaria, Viages de Enrique Wanton a las tierras incógnitas australes y al país de las Monas: en donde se expresan las costumbres, caracter, ciencias y policía de estos extraordinarios habitantes; Madrid, ediciones entre 1769-1784].

2. Yt. Un tomo Gramática inglesa en quince reales. [SAN PEDRO, Joaquín, Gramática inglesa y española, Madrid, 1769] [CONNELLY, Thomas, Gramática que contiene reglas fáciles para pronunciar y aprender metódicamente la lengua inglesa, Madrid, 1784] [STEFFAN, Juan, Gramática inglesa, y castellana, Valencia, 1784].

3. Ytem otro tomo tratado de las enfermedades más frecuentes de la gente del campo en diez y ocho reales. [TISSOT, Mr., Tratado de las enfermedades mas frequentes de las gentes del campo..., Madrid, 1776].

4. Ytem otro tomo historia de Gibraltar en diez y ocho reales [LÓPEZ DE AYALA, Ignacio, Historia de Gibraltar, Madrid, 1782].

5. Ytem otro tomo Seneca obra moral en yngles en quatro reales [SÉNECA, Lucio Anneo, Seneca's morals by way of abstracts, Londres, 1775].

6. Ytem diez y seis tomos de espectáculo de la naturaleza en español en doscientos y quarenta reales [PLUCHE, Noël Antoine: Espectaculo de la naturaleza, o conversaciones a cerca de las particularidades de la historia natural... ; Madrid, 1754]

7. Ytem otro tomo en pergamino tra ta que solo Madrid es corte en tres reales.

NÚÑEZ DE CASTRO, Alonso, Libro histórico político solo Madrid es corte, y el cortesano en Madrid, Barcelona, 1698].

8. Yt. seis tomos en octavo y francés de varias materias en seis reales.

9. Ytem otro libreto manual intitulado obra pia en dos reales [WARD, Bernardo, Obra pia, y eficaz modo para remediar la miseria de la gente pobre de España, Madrid, 1767].

\footnotetext{
46 Para la identificación de los registros del inventario se ha utilizado el portal de internet del Ministerio de Cultura "Catálogo Colectivo del Patrimonio Bibliográfico Español”. En negrita se trascribe el registro tal y como aparece en el inventario protocolizado. Entre corchetes presentamos la propuesta de identificación de la obra. Sobre los problemas de identificación de este tipo de registros bibliográficos basados en documentación notarial y reflexiones acerca de las limitaciones de esta fuente para el estudio de la cultura escrita nos remitimos a: DAWSON, op. cit, pp.13-48.
} 
10. Ytem otro tomo corto en pergamino Vida de Sn. Clemente catorce en quatro reales [REBOULET, mr., Histoire de Clement XI Pape, Avignon, 1752] O [CARACCIOLO, Vida de el papa Clemente XIV..., Madrid, 1776].

11. Ytem otro tomo de Lunarquañadido en tres reales [¿CORTÉS, Jerónimo, El non plus ultra del lunario y pronostico perpetuo general y particular para cada reyno, y provincia... ;Y ahora nuevamente reformado, y añadido, Madrid, 1764?].

12. Ytem otro tomo de Sn. francisco de sales vida devota en cinco reales [FRANCISCO DE SALES, santo, Introduccion a la vida devota; Madrid, 1771].

13. Ytem dos tomos idem de la Historia del Ymperio otomano en ocho reales. [Historia General del Imperio Othomano...; y todo convertido en castellano por D. Manuel Antonio de Mena, Madrid, 1737].

14. Yt. dos tomos de la agricultura de herrera en quatro reales [HERRERA, Alonso de: Agricultura general que trata de la labranza del campo y sus particularidades, crianza de animales, propiedades [sic] de las plantas que en ella se contienen, Madrid, 1777].

15. Yt. un otro tomo idem de los aforismos de Cornelio en seis reales [TÁCITO, Cayo Cornelio, Alma o Aphorismos de Cornelio Tácito, Amberes, 1651].

16. Ytem un tomo idem historia de las medallas en cinco reales [PATIN, Carlos, Historia de las medallas o Introducción al conocimiento de esta ciencia, Madrid, 1771].

17. Yt. un tomo idem sentinela contra judíos en tres reales [TORREJONCILLO, Francisco de, Centinela contra judíos, Barcelona, 1731].

18. Ytem un quaderno de hacer vino en dos reales [MAUPIN, El arte de hacer el vino ó Experiencias sobre mejorar todo género de vinos, así buenos como malos, al tiempo de la fermentacion: para el uso de todos los cosecheros : con los principios más esenciales sobre el modo de cuidar los vinos, Madrid, 1777].

19. Ytem un quaderno por guarismo por Cusant en un real.

20. Ytem un tomo en pasta y en francés de la nueva grammatica Española en quatro reales [SOBRINO, François, Grammaire nouvelle espagnole et Françoise, Lyon, 1784].

21. Ytem un tomo Viaje y aventura de francisco Liguat en dos reales. [Voyage et avantures de Francois Leguat \&o de ses Compagnons, en deux isles desertes des indes orientales, Londres/Amberes, 1708].

22. Primeramente un tomo de aventuras de telemaco en francés en quatro reales [SALIGNAC DE LA MOTHE, FÉNELON, François de (Arzobispo de Cambray), Les avantures de Télémaque, fils d' Ulysse ..., ediciones desde 1699]. 
23. Ytem dos tomos de tablas chronologicas de historia sagrada y profana en veinte y dos reales [CLEMENTE, Claudio, Tabla chronologica de los descubrimientos, conquistas y otras cosas memorias ilustres, assi eclesiasticas como seculares, en la Africa Oriental, India y Brasil, Zaragoza, 1676].

24. Ytem un tomo consideraciones de duelos en frances en siete reales. [BASNAGE, Jacques, Dissertation historique sur les duels et les Ordres de Chevalerie. Avec un discours preliminaire ou l'on entreprend de montrer que le duël... est une vengeance barbare, injuste \& flétrissante, Basle, 1746].

25. Ytem un tomo diccionatio portátil de Veausar en dose reales. [¿LAVOISIEN, Jean-François, Dictionnaire portatif de médecine, d'anatomie, de chirugie, de pharmacie, de chymie, d'bistoire naturelle, de botanique et de physique, Paris, 1764, 1771?]

26. Ytem dos tomos de pensamientos de Seneca en catorce reales [M. ANGLIVIEL DE LA BEAUMELLE, Pensées de Seneque...; traduites en françois, pour servir à l'éducation de la Jeunesse, Paris, 1768].

27. Ytem dos tomos de comentarios de Cesar en dies y seis reales [CESAR, Cayo Julio, Les commentaires de César / traduits du latin, Lyon, 1771].

28. Ytem cinco tomos en francés en octabo de las revoluciones de España en treinta reales [D'ORLÉANS, Joseph, Histoire des Révolutions d'Espagne depuis la destruction de L'Empire des Goths, Paris 1734].

29. Ytem quatro tomo de las obras de Nicolas Boileaur en veinte y ocho reales [BOILEAU, Nicolás, Oeuvres de M. Boileau, Evreux, 1784].

30. Ytem quatro tomos del modo de enseñar y aprehender por Mr. Rollin en cuarenta reales [ROLLIN, Charles, Modo de enseñar y estudiar las bellas letras...; Madrid, 1755].

31. Ytem dos tomos cronologia de Francia dies y seis reales. [HÉNAULT, CharlesJean-François, Nouvel abregé chronologique de l'bistoire de France, Paris, 1774].

32. Ytem quatro tomos de historia antigua por Mr. Rollin en doce reales [ROLLIN, Charles, Historia antigua de los egipcios, de los asirios, de los babilonios, de los medos, y de los persas, de los macedonios, de los griegos, de los carthagineses, y de los romanos, tomos I al XIII, Madrid, eds. entre 1755-1761].

33. Ytem dies y seis tomos en español de Historia de España por el padre Mariana en cien reales [DE MARIANA, Juan, Historia general de España, Amberes, 1737].

34. Ytem siete chicos en frances de Novaux contes desfees en dies reales [MADAME D’AUNOY, Les nouveaux contes des fées, Amsterdam, eds. entre 1715-1752]. 
35. Ytem un tomo de Paraíso del Alma Christiana en seis reales [DEL AGUILA, Atanasio, Paraiso de el alma christiana y exercicio divino de cada dia para todo fidel christiano, Sevilla 1762].

36. Yt un tomo de Le petit eu cologe en 8 reales [Le petit encologe ou Livre d'église, Paris, 1777].

37. Ytem nuevo tratado de cavalleria un tomo en tres reales [DUQUE DE NEWCASTLE, nouvean Traité de Cavalerie, Paris 1742] o [BOURGELAT, Le Nouvean Newcastle ou nouveau Traité de Cavalerie, Lyon, 1771].

38. Ytem ocho tomos de cuentos arabes en cinquenta reales [Les mille et un jour: contes persans, Lille, 1766-1783].

39. Ytem quatro tomos en octabo y español sucesos memorables del mundo en dies y seis reales [ROYAUMOND, Historia de successos memorables del mundo, Madrid, 1765].

40. Ytem nuebe tomos en frances de cartas de Madama la Marquesa en noventa reales [SÉVIGNÉ, Marie de Rabutin Chantal, Marquesa de, Recueil des lettres de Madame la Marquise de Sévigné, a Madame de Grignan, sa fille, Paris, 1738-1763].

41. Ytem un tomo del gran merito del hombre en seis reales [LE MAITRE DE CLAVILLE, Charles François Nicolas, Tratado del verdadero merito del hombre considerado en cada edad y en cada condición con principios de educación propios para instruir rectamente a la juventud, Madrid, 1741].

42. Ytem un tomo de principios generales y racionales de la Grammatica Francesa en cinco reales [Grammaire générale et raisonnée, Paris, 1756] o [ARNAULD, Antoine, Grammaire générale et raisonnée : contenant les fondemens de l'art de parler, Paris, 1780].

43. Primeramente un tomo en octabo de historia de Miss Jenny en ocho reales [RICCOBONI, Marie Jeanne de Mézières, Histoire de Miss Jenny, ecrite \& envoyée par elle á Milady, Comtesse de Roscomond, Paris 1765].

44. Yt otro tomo de Leters Writem en dos reales Philip Dormer Stanhope, (CONDE DE CHESTERFIELD), Letters written by the late Right Honourable Philip Dormer Stanhope, Earl of Chesterfield, to his son, Philip Stanhope, Londres 1777].

45. Ytem otro tomo Jounal duciege de Bergonzon ocho reales [Journal du siége de Bergop-zoom: avec réflexions militaires, Paris, 1756].

46. Ytem otro tomo Loisirs Dun Soldten quatro reales [Loisirs d'un soldat au régiment des gardes françoises, Paris, 1760].

47. Yt otro de Arte de encontrar la Verdad en un real [PIQUER, Andrés, Lógica moderna $o$ arte de hallar la verdad y perfeccionar la razón, Valencia, 1748]. 
48. Yt dos tomos anales políticos en dies y seis reales [¿LANCINA, Juan Alfonso, Commentarios políticos a los Annales de Cayo Vero Cornelio Tacito, Madrid, 1687?].

49. Yt un tomo espectáculo de la naturaleza tomo octabo fanegas en un real [PLUCHE, Noël Antoine: Le spectacle de la Nature ou entretiens sur les particularités de l'bistoire naturelle ... ; tome buitième, Francfort, 1752].

50. Yt quatro tomos Les Jorurnees Amusantes de Dicesau Roy de Madama Gomes en veinte y quatro reales [GOMEZ, Madeleine-Angélique de, Les Journées amusantes,...Amsterdam, 1766].

51. Yt. cinco tomos intitulado el Principe Eugenio en quarenta reales [TOVAR, José Rodrigo de, Historia del principe Eugenio-Francisco de Saboya, Madrid, 1738].

52. Yt.un tomo viejo de la Edad del Ymperio Otomano en un real [L'etat militaire de l'Empire Ottoman, ses progrès et sa décadence, La Haya, 1732].

53. Yt. otro tomo historia de Heredoto en un real [HERODOTO, Les histoires d'Herodote, Paris, 1713].

54. Yt. otro libro de la descripción de la ciudad de Paris en un real [BRICE, Germain, Description de la ville de Paris et de tout ce quélle contient de plus remarquable, Paris, 1753].

55. Ytem otro Manl de Praiers en dos reales [Manuel des Prières, edición no localizada].

56. Ytem otro sobre la Verdadera politica de los hombres de distinción en español en dos reales y medio [La verdadera politica de los hombres de distinción / traducida por D. Valerio de Borxa y Loaiso.., Barcelona, 1775].

57. Ytem otro viejo de Sn. Francisco de Paula en un real [GOMES DE LA CRUZ, José, Prodigiosa vida, y admirable muerte de nuestro glorioso padre San Francisco de Paula..., Madrid, 1727].

58. Ytem otro Dialogos nuebos en dos reales [Diálogos nuevos en español y francés: con muchos refranes, y las explicaciones de diversas maneras de hablar, propias á la Lengua española ..., Aviñon, 1778].

59. Ytem otro libro el perfecto Mariscal en quince reales [SOLLEYSEL, J., Le Parfait mareschal qui enseigne à connoître la beauté, la bonté et les défauts des chevaux, les signes et les causes des maladies, Paris, 1775].

60. Yt. otro en folio y pergamino la conquista de México en ocho reales [SOLÍS, Antonio de: Historia de la conquista de Mexico poblacion y progresos de la America Septentrional conocida por el nombre de Nueva España. tomo I - II, Madrid, 1783-1784].

61. Yt. otro en quarto Vida del Venerable Juan Pecador en seis reales [MASCARENAAS, Jerónimo: Vida, virtudes y maravilas del venerable ... Juan Pecador, religioso 
del Orden de San Juan de Dios y fundador del hospital de la ciudad de Xerez de la Frontera, Madrid, 1763].

62. Yt. once Comedias de Calderón en setenta y cinco reales [Calderón de la Barca, Pedro: Comedias del célebre poeta español Don Pedro Calderon de la Barca, Madrid, editadas entre 1760 y 1763].

63. Yt. varias Comedias en seis reales.

64. Ytem siete libros dobles de las obras de torres en ochenta reales [TORRES VILLAROEL, Diego, Libros en que están relatados differentes quadernos physicos, médicos, astrológicos, poéticos, morales y mysticos...; Salamanca. 1752].

65. Yt tres libros colección de ordenanzas militares, y son veinte y tres y quatro en veinte reales.

66. Ytem quatro libros Librería de Jueces en veinte y quatro reales [MARTÍNEZ, Manuel Silvestre, Libreria de jueces, utilisima, y universal, Madrid, 1774].

67. Ytem dos libros Engaños y desengaños del profano amor en doce reales [ZATRILLA Y VICO, José, Engaños, y desengaños del profano amor, deducidos de la amorosa bistoria... del Duque Don Federico de Toledo, Barcelona, 1737].

68. Primeramente un libro de la vida del venerable Padre Vidal en dos reales [Breve bistoria y narracion de la vida y muerte de ... don Fr. Thomás de Vidal y de Nin, arzobispo de la ciudad de Messina ..., Barcelona, 1749].

69. Ytem otro libro de ordenanzas de cavalletía en seis reales [Reglamento y ordenanza de S.M. para el exercicio, evoluciones, y maniobras de la Cavallería y dragones montados de sus exercitos y otros puntos relativos al servicio de estos cuerpos, Madrid, 1774].

70. Yt. dos libros de ynstrucción y examen de Albeitería en diez y seis reales [GARCÍA CABERO, Francisco, Instituciones de Albeyteria y examen de practicantes de ella, Madrid, 1748].

71. Yt. otros dos de Oricano Ylustrado en treinta reales [GUMILLA, José, El Orinoco ilustrado y defendido: Historia natural civil y geografica de este gran rio y de sus caudalosas vertientes: gobierno, usos y costumbres de los indios sus habitantes. Madrid, 1745].

72. Ytem otros dos de Madama Fouquet en veinte y quatro reales [FOUQUET, François, Obras medico-chirurgicas de Madama Fouquet; economía de la salud del cuerpo bumano, Valencia, 1771].

73. Yt. un libro de Arismetica de Puit en siete reales [PUIG, Andrés, Arithmética especulativa, y práctica, y arte de álgebra, Barcelona, 1745. 
74. Yt. otro del noble Bien educado en nuebe reales [VILA CAMPS, Antonio, El noble bien educado: instruccion politico-moral de un maestro a su discipulo, en que en un compendio de la moral-christiana se dan solidísimos documentos para la perfecta educación de un caballero, con muchas máximas importantes, y utilísimas reflexiones, Madrid, 1776].

75. Yt. otro del manejo del cavallo en Español en dies reales [¿Pluvinel, Antoine de: Breve methodo de mandar los cavallos y traerlos a la mas justa obediencia. Madrid, 1751?].

76. Yt. otro retratos de jesuitas en seis reales. [Retrato de los Jesuitas formado al natural por los más Sabios y mas Ilustres Cathòlicos : Juicio hecho de los jesuitas, Barcelona, 1768].

77. Ytem otro en quarto Noticias de la Colonias Ynglesas en siete reales [ÁLVAREZ, Francisco, Noticia del establecimiento y población de las colonias inglesas en la America Septentrional : religion, orden de gobierno, leyes y costumbres de sus naturales y babitantes, calidades de su clima, terreno, frutos ... y estado de su industria, artes, comercio y navegación, Madrid, 1778].

78. Ytem un libro de Compendio de Matemáticas en quatro reales [GODIN, Luis, Compendio de mathematicas: para el uso de los cavalleros guardias-marinas, Cádiz, 1758].

79. Ytem otro en octabo formulario de cartas en tres reales y medio [Nuevo estilo y formulario de escribir cartas misivas y responder a ellas en todos los géneros y especies de correspondencia á lo moderno. Madrid, 1777].

80. Yt. dos libros en pergamino de la Historia de España en dies reales [¿FERRERAS, Juan de, Historia de España, Madrid, 1716?].

81. Yt. otros dos sucesos memorables del mundo en dos reales [FONTAINE, Nicolás, Historia de sucesos memorables del mundo, con reflexiones instructivas para todos, Madrid, 1775].

82. Yt. un tomo idem nuebos elementos de la historia universal quatro reales [BUFFIER, Claude, Nuevos elementos de la historia universal, sagrada, y profana, de la esfera, y geographia : con un breve compendio de la historia de España, y Francia, Barcelona, 1771].

83. Yt. otro Arte Poetico Español en ocho reales [GARCÍA DE RENGIFO, Diego, Arte poetica española, Barcelona, 1759].

84. Yt. Secretos de Agricultura cinco reales [AGUSTÍ, Miquel, Libro de los secretos de agricultura, casa de campo y pastoril, Barcelona, 1781].

85. Yt. Otro Practica de testamentos de Rivia tres reales [RIPIA, Juan de la, Práctica de testamentos y modos de suceder, Madrid, 1755]. 
86. Ytem un tomo de Larraga digo Geraldo español un real [CÉSPEDES Y MENESES, Gonzalo de, Poema tragico del español Gerardo y desengaño del amor lascivo, Madrid, 1732].

87. Ytem dos brebiarios viejos en quince reales.

88. Yt. un tomo en octabo Arredondo de Albeiteria en ocho reales [ARREDONDO, Martín, Obras de Albeyteria, Madrid, 1705]

89. Yt. un tomo quaderno año Gericiense en tres reales [GUTIÉRREZ, Bartolomé, Año xericiense : diario eclesiastico, y civil de la mui noble, y mui leal ciudad de Xerez de la Frontera, Sevilla, 1755]

90. Ytem un tomo en pasta conocimiento de las catorse abes en tres reales [JAMARRO, Juan Bautista, Conocimiento de las catorce aves menores de jaula : su canto, cria y naturaleza, Madrid, 1775].

91. Ytem otro en pasta y en francés en cinco reales.

92. Ytem un tomo en pergamino de la Ymitacion de Christo en tres reales [KEMPIS, Tomás, Los cuatro libros de la imitacion de Christo y menosprecio del mundo, Madrid, 1723].

93. Ytem dos tomos en francés a la rustica en ocho reales.

94. Ytem un tomo en quarto instrucción de sacerdotes en tres reales [MOLINA, Antonio, Instrucción de sacerdotes: en que se les da doctrina muy importante para conocer la alteza del sagrado oficio sacerdotal, Barcelona, 1746].

95. Ytem un tomo de filosofia moral de Tesauro quatro reales [TESAURO, Emanuele, (conde de Salmore), Filosofia moral: derivada de la alta fuente del grande Aristoteles Stapirita...,. Madrid, 1770].

96. Ytem otro tomo Cavallería de Sn. Jorge quatro reales [CEPEDA Y GUZMÁN, Carlos Alberto, Origen, y fundacion de la imperial religión militar, y cavalleria constantiniana, llamada oy de San Jorge, que milita debaxo de la regla del doctor de la Iglesia ... San Basilio Magno, Arzobispo de Cesarea, Sevilla, 1676].

97. Ytem un tomo en octabo de Epistola de Sn. Gerónimo en quatro reales JERÓNIMO, Santo, Epistolas selectas / de ... S[a]n Geronymo, Barcelona, 1773]. 